\title{
BACTERIOLOGICAL PROFILE OF DIABETIC FOOT ULCERS WITH REFERENCE TO HbA1C LEVELS
}

\author{
Shajahan Ansar', Ayesha Dastagir ${ }^{2}$
}

${ }_{1}^{1}$ Assistant Professor, Department of Microbiology, Perundurai Medical College, Erode, Tamilnadu, India.

2Senior Assistant Professor, Department of Microbiology, Coimbatore Medical College, Coimbatore, Tamilnadu, India.

\author{
BACKGROUND \\ The prevalence of diabetes is increasing in India. Patients with diabetes mellitus may have many serious sequelae. Among them, \\ foot ulcers are most common and may lead to severe complications. \\ The present study was undertaken to determine association between HbA1c levels in relation with diabetic foot infections, \\ bacteriological profile and antibiotic susceptibility pattern.
}

ABSTRACT

\section{MATERIALS AND METHODS}

The descriptive study was carried out in the Department of Microbiology, CMC from March 2009 to Sep 2010 to look for the pattern of growth of aerobic organisms in diabetic foot ulcers.

\section{RESULTS}

Of the 100 DFI cases studied, most of the patients belonged to the $5^{\text {th }}$ and $6^{\text {th }}$ decades of life, (37\%) and (28\%) respectively. Males were more affected compared to females with a ratio of 2.3: 1. Maximum number of patients were seen in Wagner's Grade II (40 nos.) followed by Wagner's Grade III (38 nos.). Maximum number of diabetic foot ulcer cases (45) were recorded with HbA1c levels of $>10$. The total distribution of monomicrobial and polymicrobial growth was 62 and 28 respectively with the maximum number of growth recorded in HbA1c levels of more than 10. MRSA constitutes 50\% in HbA1c levels of $<8$ and 8 to 10 and $55 \%$ in $\mathrm{HbA1c}$ levels of $>10$.

\section{CONCLUSION}

The incidence of diabetic foot lesions strongly correlates with poor glycaemic control, which in itself is best manifested by the levels of glycosylated haemoglobin levels. There was significant association between DFI and higher HbA1c levels.

\section{KEY WORDS}

Diabetic Foot Infections, Glycaemic Control, Antibiotic Resistant Strains.

HOW TO CITE THIS ARTICLE: Ansar S, Dastagir A. Bacteriological profile of diabetic foot ulcers with reference to HbA1c levels. J. Evolution Med. Dent. Sci. 2018;7(45):5653-5656, DOI: 10.14260/jemds/2018/1081

\section{BACKGROUND}

Diabetes is one of the oldest metabolic disorders known to mankind. Globally, the prevalence of diabetes is expected to rise from a current estimate of 150 - 220 million in 2010 to 300 million in $2025 .^{1}$ The number of people with diabetes is increasing due to population growth, ageing, urbanisation, increasing prevalence of obesity and physical inactivity. Quantifying the prevalence of diabetes now and the number of people to be affected in future is important to allow rational planning and allocation of resources.

Patients with diabetes mellitus may have many serious sequelae. Among them, foot ulcers are most common and may lead to severe complications. ${ }^{2}$ Longstanding diabetes often results in peripheral sensory and motor neuropathy, along with foot deformities. ${ }^{3}$ Peripheral vascular disease and peripheral diabetic neuropathy increase the risk of diabetic foot ulcers leading to infections and amputations. 4 The longer nerves are more vulnerable, hence peripheral foot neuropathy is commonly seen in the foot.

'Financial or Other Competing Interest': None.

Submission 24-09-2018, Peer Review 18-10-2018,

Acceptance 25-10-2018, Published 05-11-2018.

Corresponding Author:

Dr. Shajahan Ansar,

Department of Microbiology,

\#90, JMQ K1, Sanitorium Quarters,

PMCH, Perundurai, Erode District-638053,

Tamilnadu, India.

E-mail: shajahan47878@gmail.com

DOI: $10.14260 /$ jemds $/ 2018 / 1081$
These, combined with poorly understood perturbations in host defense mechanisms and wound healing responses set the stage for diabetic foot ulcers leading to foot infections. ${ }^{5}$ Although, most of the infections remain superficial, $\sim 25 \%$ will spread contiguously from skin to deeper subcutaneous tissues and bone. ${ }^{4,6}$

The rate of infection parallels blood glucose levels. Blood glucose binds to haemoglobin in red blood cells to form glycosylated haemoglobin (HbA1c). HbA1c levels depend on blood glucose concentrations. HbA1c can be used as a time average index of the blood glucose concentration to which haemoglobin has to be exposed reflecting the glycaemic history in the previous two to three months. Glycaemic control is the prime factor in controlling the development of diabetic complications. Poor glycaemic control in diabetes has serious complications. Each $2 \%$ increase in the level of $\mathrm{HbA} 1 \mathrm{c}$ increases the risk of lower extremity ulcer by 1.6 times and the risk of lower extremity amputation by 1.5 times. ${ }^{7}$

Infections in diabetic patients are mostly polymicrobial in nature. ${ }^{8}$ In acute superficial infections of foot ulcer, aerobic gram-positive bacteria such as Staphylococcus aureus and Beta-Haemolytic Streptococci predominate.9,10 In deeply infected chronic ulcers a mixture of aerobic gram positive, aerobic gram negative and anaerobic organism are seen. ${ }^{11}$

Staphylococcus aureus was the most common pathogen among the gram-positive bacteria isolated among the Diabetic foot ulcers. The pathogenesis of staphylococcal infections is multifactorial. Infection by Staphylococci usually results from a combination of bacterial virulence factors and 
diminution in host defense.12 Wound infection can occur following an operative incision, acute traumatic laceration or chronic pressure induced ulcer, during which bacteria indigenous to the patient or exogenous to the wound overwhelm the systemic and local factors of host resistance. 13 The gram negative comprise mainly of Enterobacteriaceae family such as Escherichia coli, Klebsiella spp., Proteus spp. etc. Non-fermenters such as Pseudomonas spp. and Acinetobacter spp. have been isolated as well.

The glycosylated $\mathrm{Hb}$ test is an important blood test to diagnose DM/ determine control of DM. There is almost a direct relationship of foot lesions with increasing Glycosylated Haemoglobin. ${ }^{14,15}$

The study sought to analyse the influence of patient variables on diabetic foot ulcers. In this study, we have made an attempt to correlate $\mathrm{HbA1c}$ levels with the bacteriological profile of diabetic foot infections and the antimicrobial susceptibility pattern.

\section{MATERIALS AND METHODS}

The descriptive study was conducted in the Department of Microbiology at Coimbatore Medical College Hospital among diabetic patients with foot ulcer attending the Surgery Outpatient Department. Data collection was done over a period of $1 \frac{1}{2}$ years from March 2009 to Sep 2010. Pus and wound swabs were collected from around 100 patients with age above 20 years with Type I and Type II Diabetes mellitus shaving Diabetic Foot Ulcer. Patients on antibiotic treatment and with non-diabetic ulcers were excluded from the study. The samples received in the Department of Microbiology were processed for aerobic culture and antibiotic sensitivity testing during the study period. Blood samples were collected to analyse the HbA1c levels.

Patients were evaluated, and the data was collected with the help of questionnaire, which comprised of relevant clinical history, clinical examination and laboratory investigations. Clinical examinations involved evaluating the site, nature and extent of the wound. The ulcer type was evaluated using Wagner's classification of diabetic foot ulcers. This classification includes 6 stages of severity.

Grade 0: No obvious ulcer but thick callus, prominent metatarsal head, claw toes or any bony abnormality.

Grade 1: Superficial ulcer, not clinically infected.

Grade 2: Deeper ulcer, often infected, but no bone involvement.

Grade 3: Deep ulcer, abscess formation and bone involvement.

Grade 4: Localised gangrene.

Grade 5: Gangrene of whole foot.

\section{Statistical Analysis}

Descriptive statistics calculated for background variables. To test the association between Diabetic foot ulcer and HbA1c levels and Chi-square test was done. $\mathrm{P}$ value $<0.05$ was considered statistically significant.

\section{RESULTS}

The present study was carried out among 100 diabetic foot ulcer patients attending Department of Microbiology, CMC to look for the pattern of growth of aerobic organisms and their antibacterial susceptibility pattern. The following Tables and Figures illustrate the results in detail.

\begin{tabular}{|c|c|c|}
\hline Age in Years & Males & Females \\
\hline $21-30$ & $3(3 \%)$ & $1(1 \%)$ \\
\hline $31-40$ & $4(4 \%)$ & $1(1 \%)$ \\
\hline $41-50$ & $14(14 \%)$ & $4(4 \%)$ \\
\hline $51-60$ & $26(26 \%)$ & $11(11 \%)$ \\
\hline $61-70$ & $16(16 \%)$ & $12(12 \%)$ \\
\hline $71-80$ & $7(7 \%)$ & $1(1 \%)$ \\
\hline Total & 70 & 30 \\
\hline
\end{tabular}

Of the 100 cases studied, most of the patients belonged to the $5^{\text {th }}$ and $6^{\text {th }}$ decades of life $(37 \%)$ and $(28 \%)$ respectively. Males were more affected compared to females with a ratio of 2.3: 1 .

\begin{tabular}{|c|c|}
\hline Wagner's Grade & Number of Patients (\%) \\
\hline Grade I & $0(0 \%)$ \\
\hline Grade II & $40(40 \%)$ \\
\hline Grade III & $38(38 \%)$ \\
\hline Grade IV & $16(16 \%)$ \\
\hline Grade V & $6(6 \%)$ \\
\hline Table 2. Distribution of Ulcers according to Wagner's \\
Classification \\
\hline
\end{tabular}

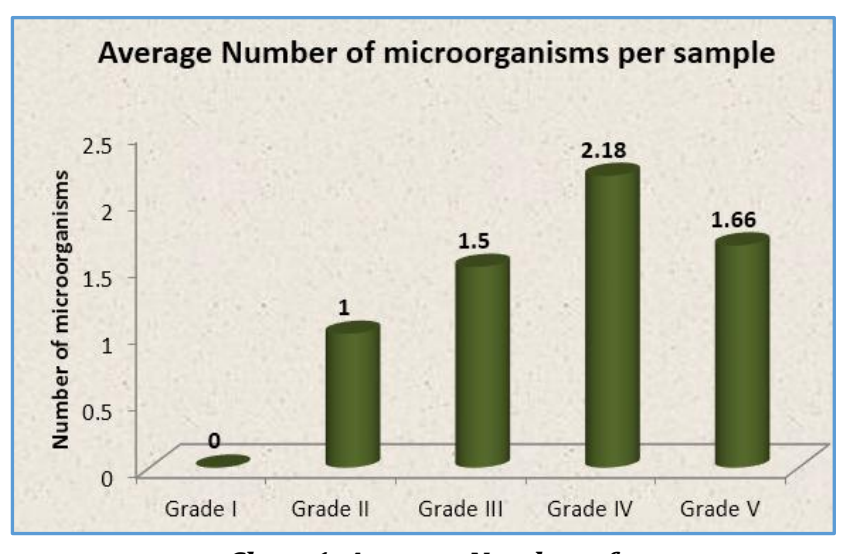

Chart 1. Average Number of Microorganisms per Sample

Average no. of aerobes per sample was found to be maximum in Grade 4 ulcers (2.18). The average number of microorganism/sample is decreasing as the Wagner's grade decreases except for Grade V, which showed average of 1.66 organisms.

\begin{tabular}{|c|c|}
\hline HbA1c Levels & No. of Patients with Diabetic Foot Ulcers \\
\hline 6 to 7 & $12(12 \%)$ \\
\hline 7 to 8 & $12(12 \%)$ \\
\hline 8 to 9 & $13(13 \%)$ \\
\hline 9 to 10 & $18(18 \%)$ \\
\hline$>10$ & $45(45 \%)$ \\
\hline Total & $\mathbf{1 0 0}$ \\
\hline \multicolumn{2}{|c|}{ Table 3. Correlation between HbA1c Levels } \\
and Diabetic Foot Ulcers \\
\hline
\end{tabular}

Maximum no. of Diabetic foot ulcer patients had HbA1c levels more than 10 . The number of patients having $\mathrm{HbA1c}$ levels above 8 was $76 \%$. 


\begin{tabular}{|c|c|c|c|c|c|c|}
\hline \multirow{2}{*}{ HbA1c } & \multicolumn{7}{|c|}{ Wagner's Grade } & Total \\
\cline { 2 - 7 } & $\begin{array}{c}\text { Grade } \\
\text { I }\end{array}$ & $\begin{array}{c}\text { Grade } \\
\text { II }\end{array}$ & $\begin{array}{c}\text { Grade } \\
\text { III }\end{array}$ & $\begin{array}{c}\text { Grade } \\
\text { IV }\end{array}$ & $\begin{array}{c}\text { Grade } \\
\text { V }\end{array}$ & \\
\hline 6 to 7 & 0 & 6 & 6 & 0 & 0 & 12 \\
\hline 7 to 8 & 0 & 6 & 3 & 1 & 2 & 12 \\
\hline 8 to 9 & 0 & 6 & 4 & 2 & 1 & 13 \\
\hline 9 to 10 & 0 & 4 & 8 & 4 & 2 & 18 \\
\hline$>10$ & 0 & 18 & 17 & 9 & 1 & 45 \\
\hline Total & 0 & $\mathbf{4 0}$ & $\mathbf{3 8}$ & $\mathbf{1 6}$ & $\mathbf{6}$ & $\mathbf{1 0 0}$ \\
\hline \multicolumn{7}{|c|}{ Table 4. Association between HbA1c Levels } \\
and Wagner's Grades \\
\hline
\end{tabular}

Table 4 shows the association between HbA1c Levels and Wagner's grades.

Maximum no. of cases (45) were recorded with HbA1c levels of $>10$. Higher grade ulcers were less in patients having HbA1c below 8. This difference was not found to be statistically significant.

\begin{tabular}{|c|c|c|c|}
\hline $\begin{array}{l}\text { HbA1c } \\
\text { Levels }\end{array}$ & $\begin{array}{c}\text { No. of } \\
\text { Monomicrobial } \\
\end{array}$ & $\begin{array}{c}\text { No. of } \\
\text { Polymicrobial }\end{array}$ & P value \\
\hline 6 to 7 & $7(7 \%)$ & $2(2 \%)$ & \multirow{5}{*}{0.837} \\
\hline 7 to 8 & $10(10 \%)$ & $5(5 \%)$ & \\
\hline 8 to 9 & $8(8 \%)$ & $4(4 \%)$ & \\
\hline 9 to 10 & $9(9 \%)$ & $4(4 \%)$ & \\
\hline$>10$ & $28(28 \%)$ & $13(13 \%)$ & \\
\hline Total & 62 & 28 & \\
\hline & $\begin{array}{r}\text { Association } \\
\text { and Micro }\end{array}$ & $\begin{array}{l}\text { een HbA1c L } \\
\text { Growth }\end{array}$ & \\
\hline
\end{tabular}

The total distribution of monomicrobial and polymicrobial growth was 62 and 28 respectively with the maximum number of growth recorded in HbA1c levels of more than 10 . This difference was not found to be statistically significant.

\begin{tabular}{|c|c|c|c|}
\hline HbA1c Levels & MRSA & MSSA & P value \\
\hline < 8 & $3(3 \%)$ & $3(3 \%)$ & \multirow{2}{*}{0.976} \\
\cline { 1 - 3 } 8 to 10 & $3(3 \%)$ & $3(3 \%)$ & \\
\cline { 1 - 2 }$>10$ & $6(6 \%)$ & $5(5 \%)$ & \\
\hline \multicolumn{3}{|c|}{ Table 6. Association between HBA C Levels and MRSA } \\
\hline
\end{tabular}

Table 6 reveals the association between HbA1c levels and MRSA. Of the 23 Staphylococcal isolates, MRSA constitutes $50 \%$ in $\mathrm{HbA} 1 \mathrm{c}$ levels of $<8$ and 8 to 10 and $55 \%$ in $\mathrm{HbA} 1 \mathrm{c}$ levels of $>10$. This difference was not found to be statistically significant.

\section{DISCUSSION}

Worldwide, Diabetic foot lesions are causing major medical, social and economic problems and the leading cause of hospitalisation for patients with diabetes. Because of serious or recurrent infections and impaired healing processes, initially trivial lesion may progress to chronic non-healing wounds, gangrene or untreatable infections that can lead to limb amputation.16 Many Diabetic foot ulcers are neglected, because they may produce few symptoms and their importance is not appreciated by the patients. ${ }^{17}$ Patients who develop foot lesions have significantly less knowledge of diabetes including foot care.

Hundred pus and wound samples were collected from patients above 20 years of age with known history of Diabetes mellitus, most of the patients belonged to the $5^{\text {th }}$ and $6^{\text {th }}$ decades of life, $(37 \%)$ and $(28 \%)$ respectively. This coincides with the studies listed below by other authors. The mean age of the patients was 59.5 years in Kahn et al study, 58 years in Ramani et al study, 58 years in Dipali AC et al study. In contrast, the mean age was reported as 75.02 years in NA Pathare et al study 18 and 43 years in study conducted by $\mathrm{C}$ Anandi et al from Tamilnadu, India. 19

In our study, the males were more affected compared to females with a ratio of 2.3: 1 . This was in concordance with the following studies, D Vijay et $\mathrm{al}^{9}$ in 2000 observed a preponderance of male patients showing diabetic foot ulcers $(72.5 \%)$ compared to female patients $(27.5 \%)$. The ratio of male-to-female was 2.6: 1 . In a study by Dipali AC et al,14 in $200267 \%$ of male patients with diabetic foot ulcers were reported against $32.4 \%$ of female patients with a ratio of 2.1:1. Prevalence of $58.5 \%$ of male patients and $41.2 \%$ of female patients with a ratio of 1.41: 1 was noted in a study by Fiaz Ur Rehman et al in 2002. Anandi et al ${ }^{19} 2004$ observed a difference of $65.4 \%$ and $54.6 \%$ among male and female patients with a ratio of 1.2: 1 . All the above authors have observed a preponderance of males in their study.

In our study, most of the ulcers belonged to Grade II of Wagner's classification followed by Grade III. The above data correlates with the results published by V Vijay et al showing $50 \%$ Grade II ulcers followed by $26.5 \%$ Grade III Ulcers. ${ }^{9}$ Out of the hundred samples, 90 yielded aerobic bacterial growth and 10 samples did not yield any growth in our study. In a study by Mohanty et al in 2002, out of 5,039 pus samples, 2437 (48.36\%) were culture positive while 1831 (33.33\%) was culture negative. ${ }^{20}$

In our study, only aerobic growth of organisms were analysed. Higher grade of diabetic foot ulcers have known to be associated with mixed flora comprising of both aerobes and anaerobes. When antimicrobial therapy is indicated for treatment of diabetic foot ulcers, the likelihood of complex aerobic and anaerobic flora should be considered, and appropriate antimicrobial agents selected. As per our study, maximum no. of patients (45) with DFI had HbA1c levels more than 10 . The number of patients with having HbA1c above 8 are $76 \%$. In a study by Nahid Rouhipour, ${ }^{21} 62.9 \%$ of patients had poor diabetes control (HbA1c of $8 \%$ or higher) and in a study by MB Girish et al the mean glycated haemoglobin was $7.80 \pm 0.80 .22$ The patients who underwent amputation presented a significantly higher incidence of ischaemic diabetic foot with HbA1c > 7. As per Wheat et al study, the majority of patients with diabetic foot ulcers had bad diabetic control status (HbA1c > 8.5). ${ }^{8}$

Among 183 diabetic individuals treated at the Johns Hopkins Wound Centre, mean HbA1c was 8.0.23 In Strohva L et al study,24 in 2006 significant number (65\%) of infected ulceration on feet was reported in poorly controlled diabetic patients with $\mathrm{HbA1c}$ above 8. Infection and osteomyelitis together remain as significant risk factor for amputation. In this study, HbA1c appears to be a significant predictor for amputation.

But in Nighat Akbar et al's study,25 though the mean value of glycosylated haemoglobin ( $\mathrm{Hb})$ was $8.2(6-16.6), 75 \%$ of patients showed an $\mathrm{HbA1}$ c level $<8.0$; in $25 \%$ cases it was $>8$. All the patients who had an HbA1c level $>10 \%$ manifested with various types of foot lesions.

In our study, maximum number of cases (45) were recorded with $\mathrm{HbA} 1 \mathrm{c}$ levels of $>10$ and most number of cases were found in Grade II and Grade III. The total distribution of 
monomicrobial and polymicrobial growth was 62 and 28 respectively with the maximum number of growth recorded in HbA1c levels of more than 10. In Shaba Tiwari et al study, ${ }^{26}$ HbA1c was same in polymicrobial and the monomicrobial infections $(9.9 \%$ versus $9.5 \% ; \mathrm{p}=0.1)$ of diabetic foot patients.

There was no relationship between the bad control diabetic status and the type of pathogen isolated from the ulcers similar as per Wheat et al study. ${ }^{9}$ In our study, the MRSA and MSSA isolates are evenly found in all the categories of $\mathrm{HbA} 1 \mathrm{c}$ levels. MRSA constitutes $50 \%$ in $\mathrm{HbA} 1 \mathrm{c}$ levels of $<8$ and 8 to 10 and $55 \%$ in HbA1c levels of $>10$.

As this is a pilot study regarding the correlation of $\mathrm{HbA1c}$ with Wagner's grade of DFI and MRSA, more research and detailed knowledge is needed in future to assess the appropriate management of DFI patients. In our study, the incidence of diabetic foot lesions strongly correlates with the poor glycaemic control, which in itself is best manifested by the levels of glycosylated $\mathrm{Hb}$.

\section{CONCLUSION}

The incidence of diabetic foot lesions strongly correlates with poor glycaemic control, which in itself is best manifested by the levels of glycosylated haemoglobin levels. There was significant association between DFI and higher HbA1c levels. But no correlation was found between HbA1c levels and the polymicrobial nature of infection and prevalence of MRSA in DFI. Further research is needed to study about correlation of HbA1c levels with other factors in DFI and important studies need to be performed to overcome the serious problem of foot ulceration in diabetes mellitus.

\section{REFERENCES}

[1] Larsen PR, Kronenberg HM, Melmed S, et al. Complications of diabetes mellitus. Williams Textbook of Endocrinology. 10 th edn. 2003: p. 1427-83.

[2] Frykberg RG, Armstrong DG, Giurini J, et al. Diabetic foot disorders: clinical practice guideline. American College of Foot and Ankle Surgeons. J Foot Ankle Surgery 2000;39(Suppl 5):S1-S60.

[3] Boulton AJM. The diabetic foot. Medical Clinics of North America 1988;72(6):1513-30.

[4] Lipsky BA. Medical treatment of diabetic foot infections. Clinical Infectious Disease 2004;39(Suppl 2):S104-S14.

[5] Apelqvist J, Bakker $\mathrm{K}$, Van Houtum WH, et al. International consensus and practical guidelines in the management and the prevention of the diabetic foot. Diabetic International Working Group on the Diabetic foot cases. Diabetes Metab Res Rev 2000;16(Suppl 1):S84-S92.

[6] Edmonds ME. The diabetic foot: pathophysiology and treatment. Clinics in Endocrinology and Metabolism 1986;15(4):889-916.

[7] Stevens VJ, Vlassara H, Abati A, et al. A non-enzymatic glycosylation of haemoglobin. J Biol Chem 1977;252(9):2998-3002.

[8] Wheat LJ, Allen SD, Henry M, et al. Diabetic foot infections - bacteriological analysis. Arch Intern Med 1986;146(10):1935-40.
[9] Vijay V, Narasimham DV, Seena R, et al. Clinical profile of diabetic foot infections in South India: a retrospective study. Diabetic Med 2000;17(3):215-8.

[10] Louie TJ, Bartlett JG, Tally FP, et al. Aerobic and anaerobic bacteria in diabetic foot ulcers. Annals of Internal Medicine 1976;85(4):461-3.

[11] Sharp CS, Bessman AN, Wagner FW Jr, et al. Microbiology of superficial and deep tissues in infected diabetic gangrene. Surg Gynaecol \& Obstet 1979;149(2):217-9.

[12] Ulbrecht JS, Cavanagh PR, Caputo GM. Foot problems in diabetes: an overview. Clinical Infectious Diseases 2004;39(Suppl 2):S73-S82.

[13] Moreillon P. Staphylococcus aureus (including staphylococcal toxic shock). In: Mandell GL, edr. Mandell, Douglas \& Bennett's Principles and practices of infectious diseases. Philadelphia: Elsevier 2005.

[14] Chincholikar DA, Pal RB. Study of fungal and bacterial infections of the diabetic foot. Indian J Pathol Microbiol 2002;45(1):15-22.

[15] Muter BA, WajdiJabbar M, Mahdi MA. Bacteriological study of diabetic foot ulcer and it's relation to metabolic control in AL-Nassriah city, Iraq. J Thai Qar Sci 2012;3(2):40-6.

[16] Citron DM, Goldstein EJ, Merrrim CV, et al. Bacteriology of moderate to severe diabetic foot infections and in vitro activity of antimicrobial agents. Journal of Clinical Microbiology 2007;45(9):2819-28.

[17] Bamberger DM, Daus GP, Gerding DN. Osteomyelitis in the feet of diabetic patients. The American Journal of Medicine 1987;83(4):653-60.

[18] Pathare NA, Bal A, Talvalkar GV, et al. Diabetic foot infections: a study of microorganisms associated with the different Wagner grades. Indian J Pathol Microbiol 1998;41(4):437-41.

[19] Anandi C, Alaguraja D, Natarajan V, et al. Bacteriology of diabetic foot lesions. Indian J Med Microbiol 2004;22(3):175-8.

[20] Mohanty S, Kapil A, et al. Bacteriological and antimicrobial susceptibility patterns of clinical isolates of staphylococcus aureus in Nepal. Clinical Microbiology and Infectious Diseases 2005;11(3):452.

[21] Rouhipour N, Hayatshahi A, Nikoo MK, et al. Clinical microbiology study of diabetic foot ulcer in Iran: pathogens and antibacterial susceptibility. African Journal of Microbiology 2012;6(27):5601-8.

[22] Girish MB, Kumar TN, Srinivas R. Pattern of antimicrobials used to treat infected diabetic foot in a tertiary care hospital in Kolar. Int J Pharm Biomed Res 2010;1(2):48-52.

[23] Christman AL, Selvin E, Margolis DJ, et al. Hemoglobin A1c predicts healing rate in diabetic wounds. Journal of Investigative Dermatology 2011;131(10):2121-7.

[24] Strohva L. Influence of infection on clinical picture of diabetic foot syndrome. Science edition, 2006.

[25] Akbar N, Bilal N. Relation of glycemic control with diabetic foot lesions. International Journal of Pathology 2004;2(2):90-3.

[26] Tiwari S, Pratyush DD, Dwivedi A, et al. Microbiological and clinical characteristics of diabetic foot infections in northern India, 2008-2009. J Infect Dev Ctries 2012;6(4):329-32. 